Article

\title{
An Assessment of the Functional and Ecological Aspect of Novel Intermittent Stream Valves for Spraying Seed Potatoes
}

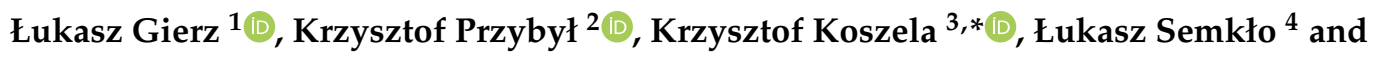 \\ Sebastian Kwiecień ${ }^{5}$ \\ 1 Faculty of Civil and Transport Engineering, Poznań University of Technology, ul. Piotrowo 3, \\ 60-965 Poznań, Poland; lukasz.gierz@put.poznan.pl \\ 2 Institute of Food Technology of Plant Origin, Poznań University of Life Sciences, ul. Wojska Polskiego 31, \\ 60-624 Poznań, Poland; kprzybyl@up.poznan.pl \\ 3 Institute of Biosystems Engineering, Poznań University of Life Sciences, ul. Wojska Polskiego 50, \\ 60-625 Poznań, Poland \\ 4 Faculty of Environmental Engineering and Energy, Poznań University of Technology, ul. Piotrowo 3, \\ 60-965 Poznań, Poland; lukasz.semklo@put.poznan.pl \\ 5 Institute of Law, John Paul II Catholic University of Lublin, Al. Racławickie 14, 20-950 Lublin, Poland; \\ sebastian.kwiecien@kul.pl \\ * Correspondence: koszela@up.poznan.pl; Tel.: +48-502-288-097
}

Received: 11 January 2020; Accepted: 3 April 2020; Published: 9 April 2020

check for updates

\begin{abstract}
It is important to protect potatoes from insects and diseases at an early stage of their development. Pesticides are necessary to prevent loss caused by Colorado potato beetles feeding on potato leaves. Nowadays, there are attempts to reduce the use of chemical agents to the minimum necessary level. This article describes the construction of a novel valve that applies chemicals in an intermittent stream during potato treatment. Thus, it is possible to reduce the emission of chemicals to the natural environment. The article also describes the research site where the valve was tested, provides the results of laboratory investigations on different types of sprayer nozzles and their validation. Apart from that, the degree of the seed potato surface covering with the dressing was assessed in order to select the right sprayer nozzle and working pressure. The results of field tests of the seed dresser prototype with novel nozzles showed that they effectively dressed seed potatoes while saving 2 L (50\%) of the chemical per hectare. Fissure sprayers achieved the highest degree of covering (up to $78 \%$ ) with the first version of the valve (without auxiliary airflow). When the innovative valve (the second solution with auxiliary airstream) was applied at distance of $50 \mathrm{~mm}$ from the seed potato fall path $S$, the highest degree of coverage with the dressing substance (up to 88\%) was observed for the ejector sprayer. When the distance between the valve and the seed potato fall, path $S$ was increased from 50 to $100 \mathrm{~mm}$, the degree of surface coverage was lower for both of the valves used in the tests.
\end{abstract}

Keywords: potato; dressing; degree of coverage; intermittent stream

\section{Introduction}

The potato is one of the most common agricultural produce in Europe and other continents [1]. It ensures food security for the increasing population all over the world [2,3]. Potatoes have a higher nutritional value per plantation area than other crops $[4,5]$. They are essential food in developing countries, and their consumption is growing continuously [6]. For more than a decade, potato consumption in developing countries has been at a similar level as in developed countries [7-9]. 
As potato consumption is so high, it is necessary to remember that the cultivation may differ considerably in various regions of the world [10-12]. Potato consumption depends on changes in temperature, rainfall, and climate in different parts of the world. They need to be taken into consideration when predicting farm business risk [13,14]. Crop protection products, especially pesticides, are used in standard potato cultivation all over the world. Consumers are increasingly concerned about the amount of chemicals used in vegetable production because they affect their health [15]. Since 2014 the rules of integrated pest management have been applied. They allow the use of all crop protection methods while minimising risk to people, animals, and the environment. The rules give priority to the most effective techniques of using crop protection products, including the machines and devices, limiting the amount of chemicals used [16]. Most countries in Europe and around the world try to protect the natural environment and give priority to ecological aspects $[17,18]$. Therefore, environmental risks should be taken into consideration. The use of crop protection products is an essential element of cultivation due to the safety of the natural environment, groundwaters, and human health [19]. The loss of seed potatoes during the growing season depends on numerous conditions, which cannot be completely eliminated. Nevertheless, there are some methods which may improve the yield and minimise loss, e.g., good knowledge of agricultural science and potato treatment. The latter method secures potatoes against pests (aphids, Colorado beetles, wireworms and grubs) as well as silver scurf, potato scab and potato rhizoctonia.

In order to ensure protection against pathogens and other diseases, potatoes need to be dressed as early as the first stage of their growth. Potato scab is a disease caused by the Helminthosporium solani fungus, which develops on the potato tuber peel during storage [20]. It causes sprouting problems in spring [21]. Potato rhizoctonia is caused by the Corticium vagum B. and C. var. solani Burt fungus. Sclerotinia (stages of Rhizoctonia mycelium) on tubers resemble lumps of soil. After, these fragments are black with the purple hue. Sclerotinia can be unevenly spread, and its size ranges from 0.5 to $5 \mathrm{~mm}$. Research has shown that Rhizoctonia develops best in acidic soil with high humus content [22]. Soil pests cause a substantial loss of crops because they damage potato tubers immediately. Although crop rotation is used in fields, polyphagous larvae still have favourable conditions for growth and reproduction. The larval stage may last 3-5 years, depending on the species (wireworms, grubs)-The knowledge of agricultural science and potato treatment help to reduce the development of pests [23].

Crops, especially seed potatoes, can be protected by dressing them with chemicals before planting. The procedure should be done precisely [24]. The oldest treatment method consists of immersing potatoes in a dressing solution $[25,26]$. According to the Polish standard (PN-R-36560:1987P), stationary seed dressing equipment, as well as sets with planters, are used to treat seed potatoes. The latter might be mobile dressing units mounted on planters. They are gaining popularity. Due to the diversified and complex construction of dressing machines [27] and about a dozen types of planters with different types of planting elements [28], there may be differences in the degree of seed potato covering with the dressing substance. As a result, increased amounts of chemicals may enter the soil. The construction of a planting unit affects the number of seed potatoes taken by one element or elements without seed potatoes. This affects the distribution of seed potatoes in a row. The aim of continuous development and globalisation of agricultural production is to cut costs. Therefore, multi-row planters with wide spaces between the rows are used increasingly often.

At the moment, dressing machines with continuous outflow of the working liquid, such as Grimme or ApliTech, are available on the market. As seed potatoes are spaced from each other when planted, chemicals could also be applied at intervals in an intermittent stream of the working liquid. In view of this fact, a novel electronically controlled valve with an auxiliary airstream dedicated to a mobile seed potato planter has been designed and constructed. The concept of the equipment has been patented [29-31].

The success, which is a result of scientific research and development, needs to be protected by law. The innovation, which is an invention meeting technical criteria, can be protected by patent, i.e., the exclusive right to use the invention for commercial purposes in Poland. Unfortunately, inventors 
often forget about it. They do not apply for patent protection, or they do it too late [32]. Entrepreneurs who have the right to the invention may choose to protect their ideas as a business secret of an enterprise, which does not have to be revealed. This solution belongs only to entrepreneurs. Other persons who want to protect their ideas and get financial benefits have to start the time-consuming patent procedure $[33,34]$.

The design documentation of a mobile dressing machine with a novel valve with an auxiliary airstream enabling intermittent outflow of the working fluid was used to build a prototype. Next, it underwent laboratory and field tests. The aim of the study was to assess the degree of potato coverage with the dressing substance flowing from a valve with an auxiliary airstream (innovative valve) and from a valve without an auxiliary airstream. The utilitarian goal was to determine the effectiveness of dressing with the innovative valve in field tests. A prototype dressing machine was constructed for this purpose. The innovative valve with an auxiliary airstream is supposed to dress potatoes with intermittent flow of the working liquid.

\section{Materials and Methods}

There were two phases of laboratory tests. In the first phase, the working liquid was applied to seed potatoes. In the second phase photographs of potatoes were taken to assess the degree of their coverage with the working liquid. The first phase of the tests was carried out at a measuring facility, which was built for the purposes of this research. Its diagram is shown in Figure 1. The facility for dressing seed potatoes was equipped with four novel valves, and a $250-\mathrm{mm}$ pipe with a diameter of $60 \mathrm{~mm}$ for guiding seed potatoes (1), in which a sensor (8) detecting seed potatoes was installed. The facility was equipped with a bar (7) with spits (3) to catch the falling seed potatoes after treatment. There was also a feed system in the form of a pump, which enabled supply at a pressure up to $800 \mathrm{kPa}$ (4) with an overflow valve within 0-1000 kPa (9) powered by an electric engine (5). The facility had a system generating a continuous stream of compressed air with a valve regulating pressure within 0-800 kPa (10) (marked in black) and a system feeding the working liquid (marked in red). The measuring facility was used in a previous study $[27,30]$, which resulted in a decision to modify the valve and the control system.

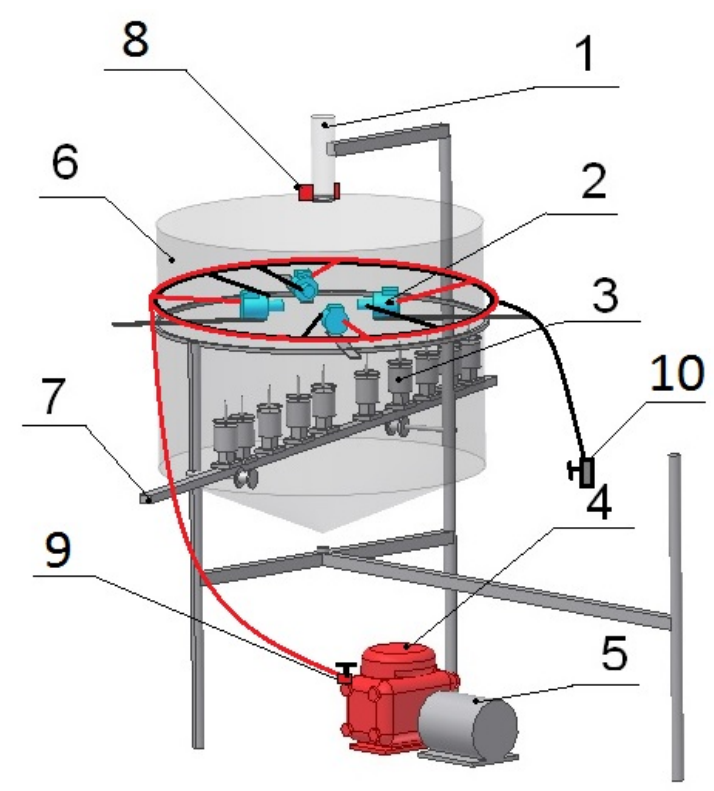

Figure 1. A diagram of the measuring facility with electronically controlled valves for dressing seed potato tubers. 1-pipe with optic sensor for guiding the potato fall path, 2 -electromagnetic valve sprayer with cover, 3 -spikes for spearing potatoes, 4-a diaphragm pump with a pressure valve, 5-electric engine, 6-bowl for collecting excess working liquid, 7-bar with spikes, 8-sensor, 9 -overflow valve, 10 - valve regulating pressure. 
The installation of a multifunctional card Advantech PCI-1710, (Advantech, Warsaw, Poland) with a preset control algorithm was a major alteration in the control system. The algorithm was written in the RAD Delphi Embarcadero 2010 (Borland, Austin, United States) environment.

Figure 2 shows the interface of the original software controlling novel valves in the measuring facility. The algorithm of the software is used for the precision setting of the working parameters of the novel valve. These are the valve opening delay and the working time, i.e., the seed potato spraying time. The delay was set at $65 \mathrm{~ms}$, whereas the valve opening (operation) time was set at $80 \mathrm{~ms}$. The parameters were determined experimentally. The test was conducted on sorted seed potatoes, which were $45-50 \mathrm{~mm}$ in diameter. The seed potatoes were painted with white emulsion paint, whereas the working liquid had the form of colour ink. Representative (model) liquid, which had been tested in previous studies, was used for this purpose [35,36].

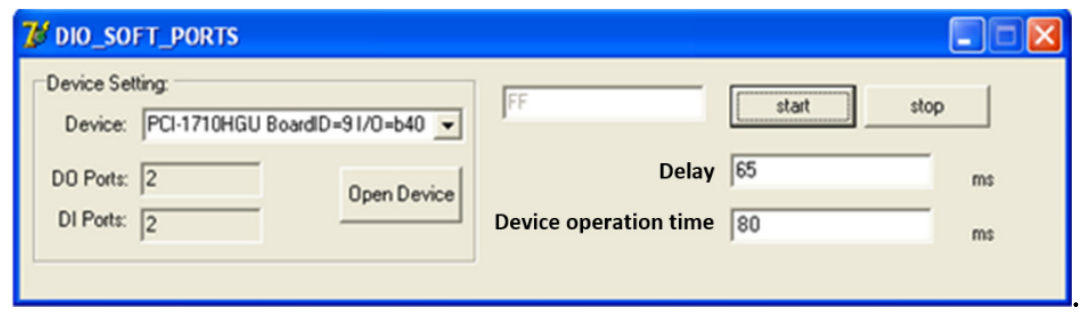

Figure 2. A window of the software controlling the electromagnetic valves.

After being dressed, the potatoes were taken to the second module (to the second phase) of the test facility with a lightbox, halogen lighting, and a rotating stool, which enabled photographing objects from 8 directions on a perfectly black background. Eight photographs of each sprayed potato were taken. The photographs and the original POKRYCIE software (Poznan, Poland), which was described in the previous publication [30], were used to measure the degree of potato covering with the dressing liquid with an accuracy of 1\%. The photographs were taken with a Nikon D3000 (Nikon Corporation, Tokyo, Japan) digital camera. The images were saved in the RAW format in order to eliminate mistakes caused by lossy compression.

In order to check if the device with novel valves worked correctly, the following types of sprayer nozzles were selected: fissure nozzle, rotary nozzle, and ejector nozzle. The basic parameters of the sprayer nozzles are listed in Table 1.

Table 1. Wipro sprayers [37].

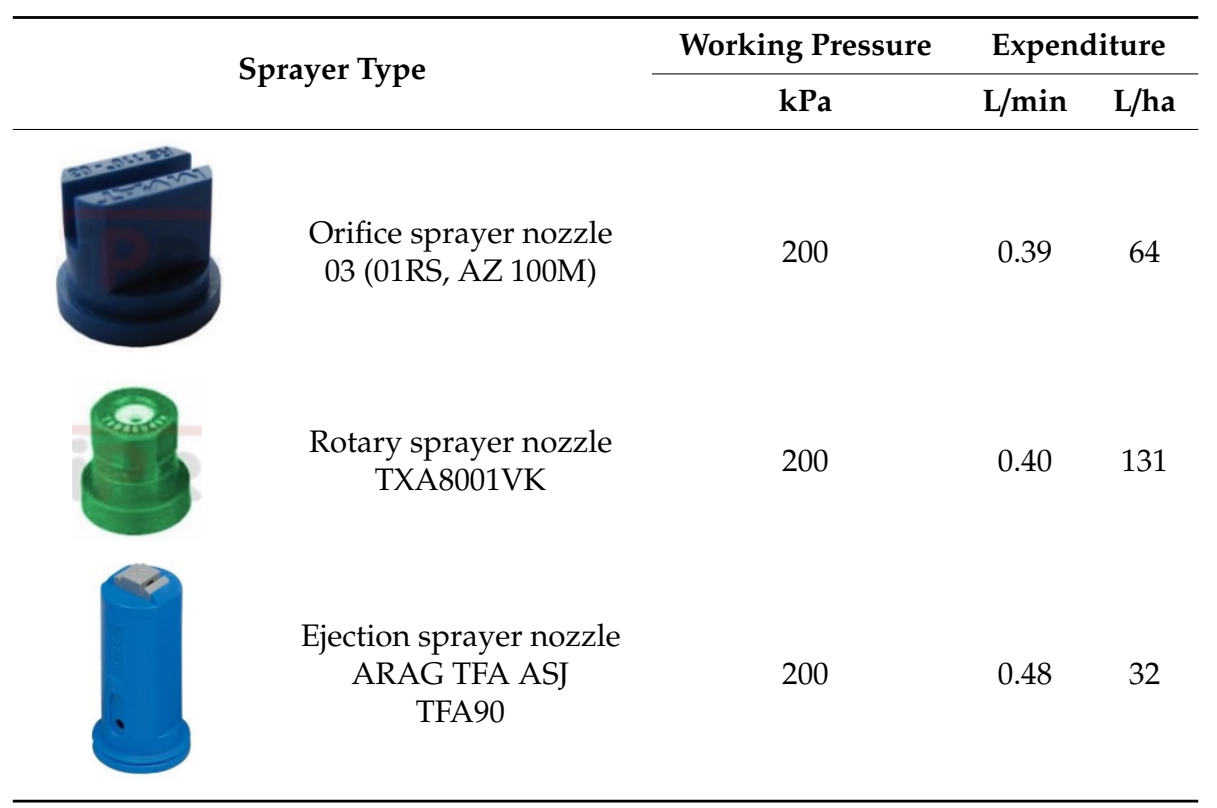


The laboratory tests were conducted at a constant temperature $(\mathrm{T})$ of $24.4{ }^{\circ} \mathrm{C}$ and relative air humidity (W) of $45 \%$. During the whole experiment, the air parameters were controlled by a Benetech GM9 Thermohygrometer (Benetech, Kalisz, Poland). It measured temperature with an accuracy of $0.5^{\circ} \mathrm{C}$ and humidity with an accuracy of $2 \%$.

There were the following variable parameters:

- the distance between the sprayers and the seed potato fall axis $S: 50,100 \mathrm{~mm}$;

- $\quad$ the working fluid pressure $p$ : 100, 200, $300 \mathrm{kPa}$;

- the types of sprayer nozzles: orifice, rotary, ejection;

- the solenoid valve variant: without an auxiliary airstream, with an auxiliary airstream.

The results were analysed statistically with the STATISTICA software (StatSoft, Warsaw, Poland). It included a multi-way analysis of variance at a confidence level of $\alpha=0.05$, which showed that all the four parameters under analysis, i.e., the sprayer distance, the working liquid pressure, the auxiliary airstream, and the sprayer type significantly influenced the coefficient of variation.

The secondary aim of the research was to devise the construction of a valve with an intermittent stream of the working liquid which would ensure an acceptable degree of seed potato covering with the dressing substance. The construction of the valve should reduce the amount of the chemical substance not to pollute the soil and ground waters with pesticides.

In order to achieve the secondary goal, i.e., an intermittent stream of the working liquid, the effective working time of the sprayer during the seed potato dressing process was calculated. Potatoes are planted at a rate of $2 \mathrm{~ms}^{-1}$ and spaced at $0.25 \mathrm{~m}$. There is a time interval of $1 / 8 \mathrm{~s}$ between consecutive seed potatoes. In the meantime, the seed potato travels a distance of roughly $0.37 \mathrm{~m}\left(1 / 8 \mathrm{~s} \times 3 \mathrm{~ms}^{-1}=\right.$ $3 / 8 \mathrm{~m})$ in the air under the influence of gravitation. During planting seed potatoes are dropped from a height of $0.2 \mathrm{~m}$ at an initial velocity of $0.1 \mathrm{~ms}^{-1}$ and an average velocity of $3 \mathrm{~ms}^{-1}$. In order to spray (dress) a potato with a model diameter of $0.05 \mathrm{~m}$, which is falling past a sprayer, a time of roughly $0.017 \mathrm{~s}$ is sufficient $\left(0.05 \mathrm{~m} / 3 \mathrm{~ms}^{-1}=1 / 60 \mathrm{~s}\right)$. If eight seed potatoes are dropped within 1 second, the time that is necessary to spray them with the dressing liquid is $0.136 \mathrm{~s}(8 \times 0.017 \mathrm{~s})$. This means that for the rest of the time, the valve can be closed. Given these calculations, we can formulate the hypothesis that by using a valve with intermittent airstream, the emission of the chemical agent (dressing substance) can be reduced for the benefit of the natural environment. Simultaneously, potatoes will be sufficiently covered with the dressing liquid. The degree of seed potato covering with the dressing liquid should be understood as the ratio of the seed potato surface dressed with the chemical agent to the total seed potato surface [30]. In order to build a prototype of a seed dressing machine with reduced emission of chemical agents (dressing substance), it was necessary to construct an electronically controlled valve with an intermittent stream of the working liquid. A project of AutoCAD 3D model of the first version of the valve is shown in Figure 3. Preliminary research showed that it was necessary to improve the valve because the stream of the working liquid did not sufficiently cover seed potatoes.

The first version of the solenoid valve was improved by adding an altered fixing nut (2) and a mixing insert (3) so that a continuous airstream at a set pressure could be generated. The valve is shown in Figure 4. An auxiliary airstream at a set pressure is supplied to the valve through the fixing nut (2), and then it flows through the mixing insert to the sprayer nozzle (1). When power is supplied, the needle is displaced and the dressing substance is injected into the sprayer. The alteration to the valve has reduced the time necessary for the liquid to be injected at the right flow. This effect was achieved by supplying compressed air to the fixing nut (2), which does not allow the pressure inside the sprayer nozzle to fall below a set level. Thanks to this modification, the dressing substance discharged from the sprayer reaches the set velocity faster. It results in a similar degree of seed potato covering with the dressing substance and its lower consumption. 


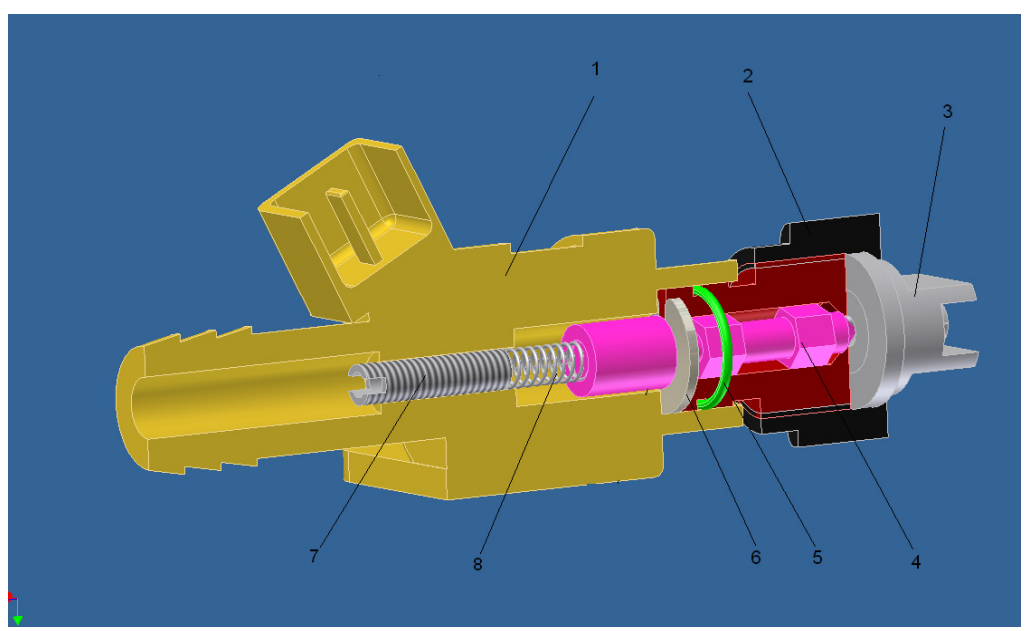

Figure 3. An electronically controlled sprayer valve, 1-body with coil, 2-nut fixing sprayer nozzle, 3-sprayer nozzle, 4-needle, 5-O-ring, 6-restrictive washer, 7-stretching screw, 8-spring.

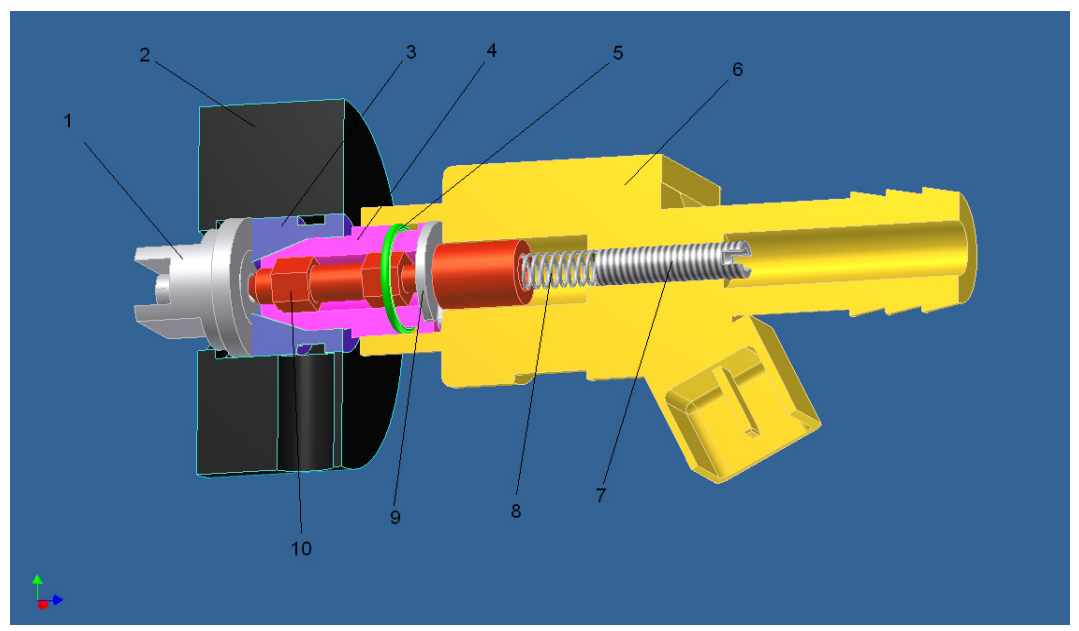

Figure 4. An electronically controlled sprayer valve with an additional supply of compressed air: 1-sprayer nozzle, 2-nut fixing sprayer nozzle to compressed air supply, 3-mixing insert, 4-needle body, 5-O-ring, 6-body with a coil, 7-stretching screw, 8-spring, 9-restrictive washer, 10—needle.

\section{Results}

Following the research schedule and having verified the construction of the planter, the novel sprayers were set at distances of $50 \mathrm{~mm}$ and $100 \mathrm{~mm}$ from the seed potato fall axis $S$. The working liquid pressure $p$ was set at 100, 200, and $300 \mathrm{kPa}$. The results of tests for the first version and modified (novel) version of the valve are listed in Table 2. The degree of seed potato covering with the dressing substance reached the maximum value of almost $90 \%$ when the ejection sprayer in the novel valve was applied at a working liquid pressure $p$ of $300 \mathrm{kPa}$ and a $50-\mathrm{mm}$ distance $S$ of the seed potato from the nozzle. What is interesting, the lowest level of seed potato covering with the dressing substance was noted for the ejection sprayer. It amounted to $28 \%$ for the first version of the valve (without an additional stream of compressed air) placed at a distance $S$ of $100 \mathrm{~mm}$ from seed potatoes. Table 2 also shows an increase and decrease in the degree of seed potato covering with the dressing substance. The highest increase was noted in the rotary sprayer at a working pressure $p$ of $300 \mathrm{kPa}$. The increase in the degree of seed potato covering with the dressing substance amounted to $109.38 \%$ when the nozzle was positioned at a distance $S$ of $100 \mathrm{~mm}$ from the seed potato fall axis. The greatest decrease, i.e., $20.45 \%$, occurred when the ejection sprayer was used, despite an additional supply of compressed air in the valve. The decrease was also observed when the working liquid pressure $p$ was $300 \mathrm{kPa}$. 
Table 2. The percentage of seed potato covering with the dressing substance.

\begin{tabular}{|c|c|c|c|c|c|c|c|}
\hline \multirow{3}{*}{$\begin{array}{l}\text { Type of } \\
\text { Sprayer }\end{array}$} & \multirow{3}{*}{$\begin{array}{l}\text { Pressure } p \\
\quad(\mathrm{kPa})\end{array}$} & \multirow{2}{*}{\multicolumn{2}{|c|}{$\begin{array}{c}\begin{array}{c}\text { Valve Without } \\
\text { Additional Stream } \\
\text { of Compressed Air }\end{array} \\
\text { Distance } S\end{array}$}} & \multirow{2}{*}{\multicolumn{2}{|c|}{$\begin{array}{c}\begin{array}{c}\text { Valve with Additional } \\
\text { Stream of Compressed Air }\end{array} \\
\text { Distance } S\end{array}$}} & \multirow{2}{*}{\multicolumn{2}{|c|}{$\begin{array}{c}\text { Increase (+) /Decrease (-) } \\
\text { in Seed Potato Covering with } \\
\text { Dressing Substance (\%) } \\
\text { Distance } S\end{array}$}} \\
\hline & & & & & & & \\
\hline & & $50 \mathrm{~mm}$ & $100 \mathrm{~mm}$ & $50 \mathrm{~mm}$ & $100 \mathrm{~mm}$ & $50 \mathrm{~mm}$ & $100 \mathrm{~mm}$ \\
\hline \multirow{3}{*}{ Orifice } & 100 & 57 & 37 & 69 & 63 & +21.05 & +70.27 \\
\hline & 200 & 76 & 63 & 67 & 61 & -11.84 & -3.17 \\
\hline & 300 & 63 & 58 & 71 & 67 & +12.70 & +15.52 \\
\hline \multirow{3}{*}{ Rotary } & 100 & 46 & 37 & 63 & 65 & +36.96 & +75.67 \\
\hline & 200 & 59 & 53 & 60 & 64 & +1.69 & +20.75 \\
\hline & 300 & 40 & 32 & 47 & 67 & +17.50 & +109.38 \\
\hline \multirow{3}{*}{ Ejection } & 100 & 38 & 28 & 66 & 29 & +73.68 & +3.57 \\
\hline & 200 & 49 & 48 & 86 & 44 & +75.51 & -8.33 \\
\hline & 300 & 61 & 44 & 88 & 35 & +44.26 & -20.45 \\
\hline
\end{tabular}

The research results were also presented in charts for distances of $50 \mathrm{~mm} \mathrm{~S}$ (Figure 5) and $100 \mathrm{~mm}$ $S$ (Figure 6) from the seed potato fall axis. Both charts show the degree of seed potato covering with the dressing substance for the first version of the valve (without an auxiliary airstream). The charts in Figures 7 and 8, respectively, show the degree of seed potato covering with the dressing substance for distances of $50 \mathrm{~mm}$ and $100 \mathrm{~mm} S$, for the novel valve (with auxiliary airstream).

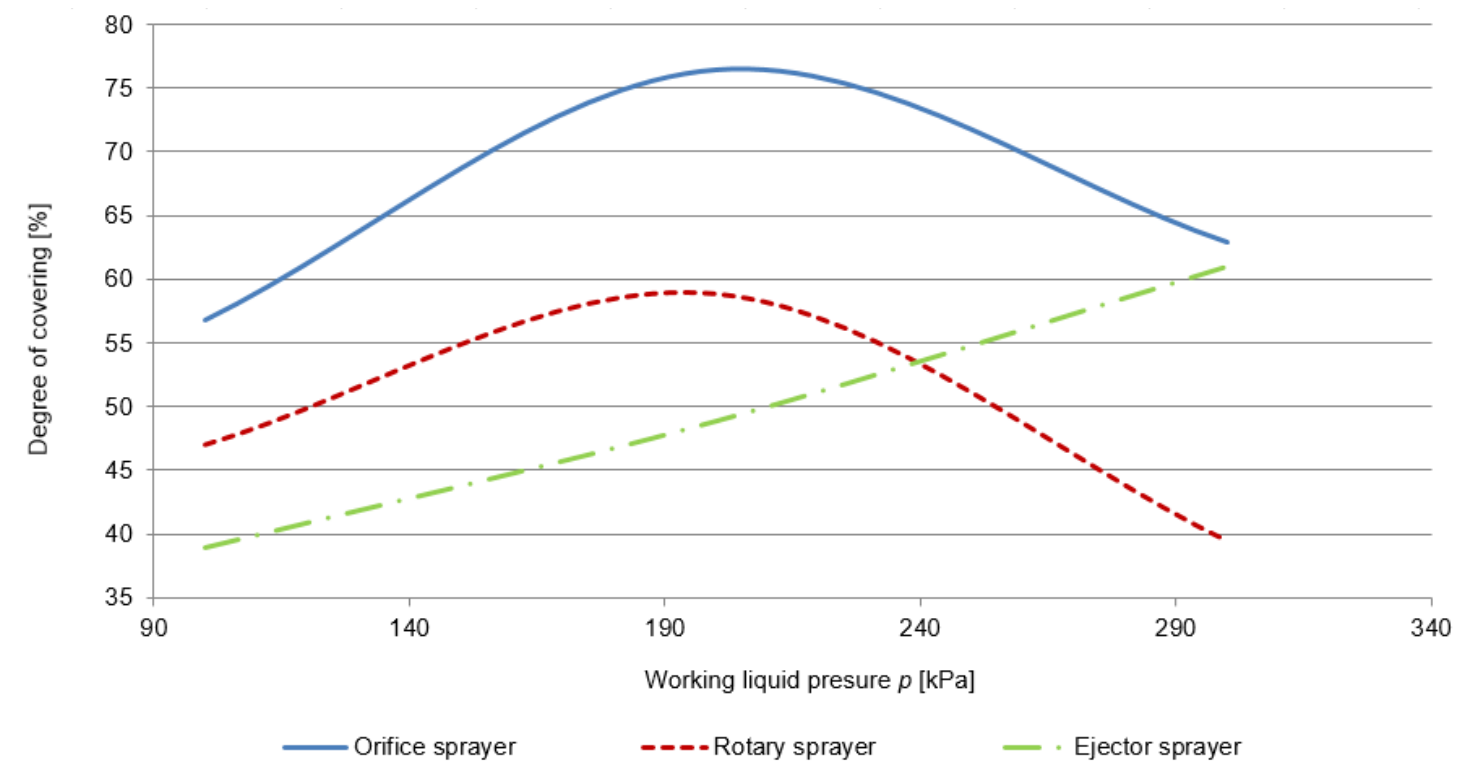

Figure 5. The degree of seed potato covering with the dressing substance for the electronically controlled sprayer valve positioned at a distance $S$ of $50 \mathrm{~mm}$ from the seed potato fall axis. 


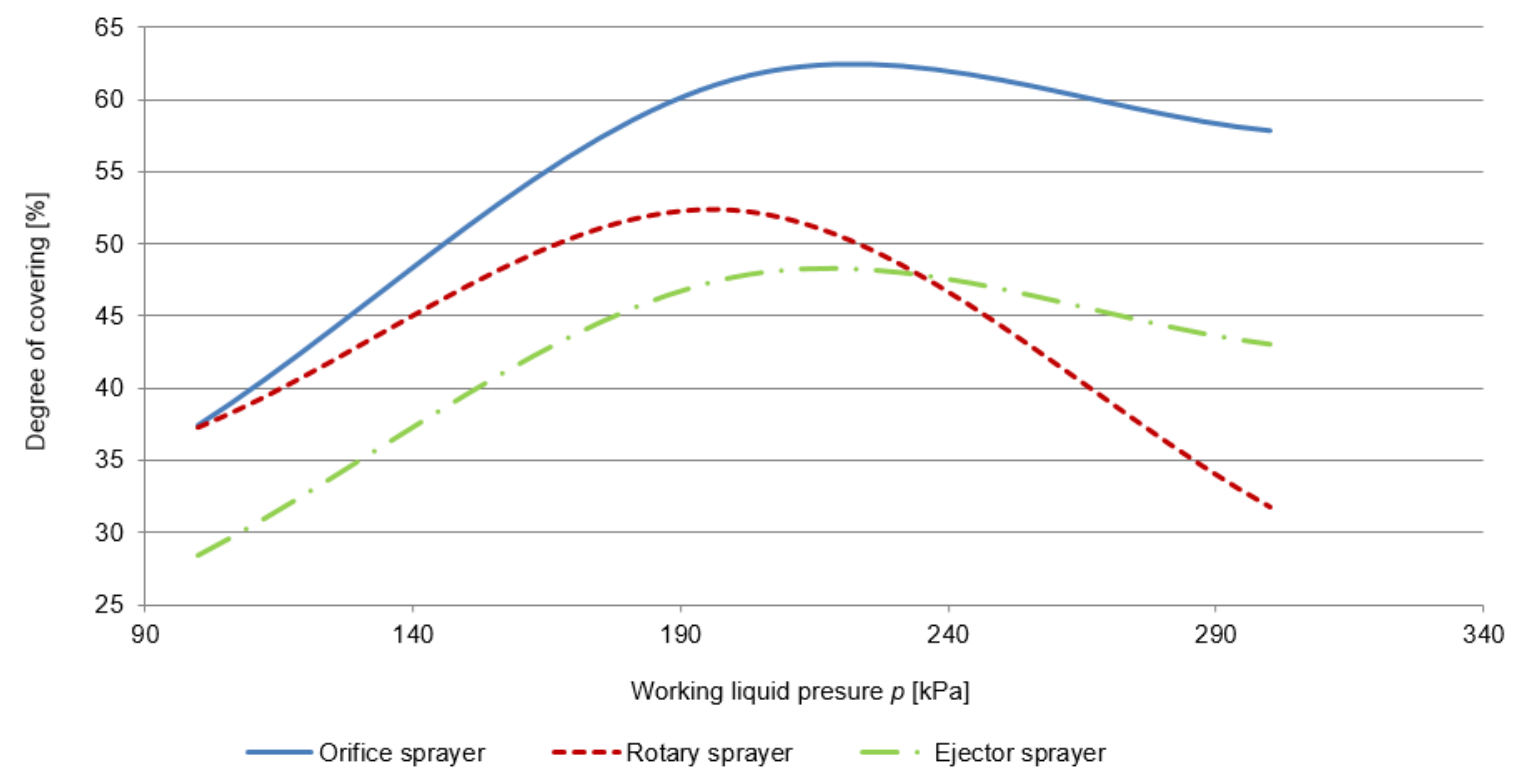

Figure 6. The degree of seed potato covering with the dressing substance for the electronically controlled sprayer valve positioned at a distance $S$ of $100 \mathrm{~mm}$ from the seed potato fall axis.

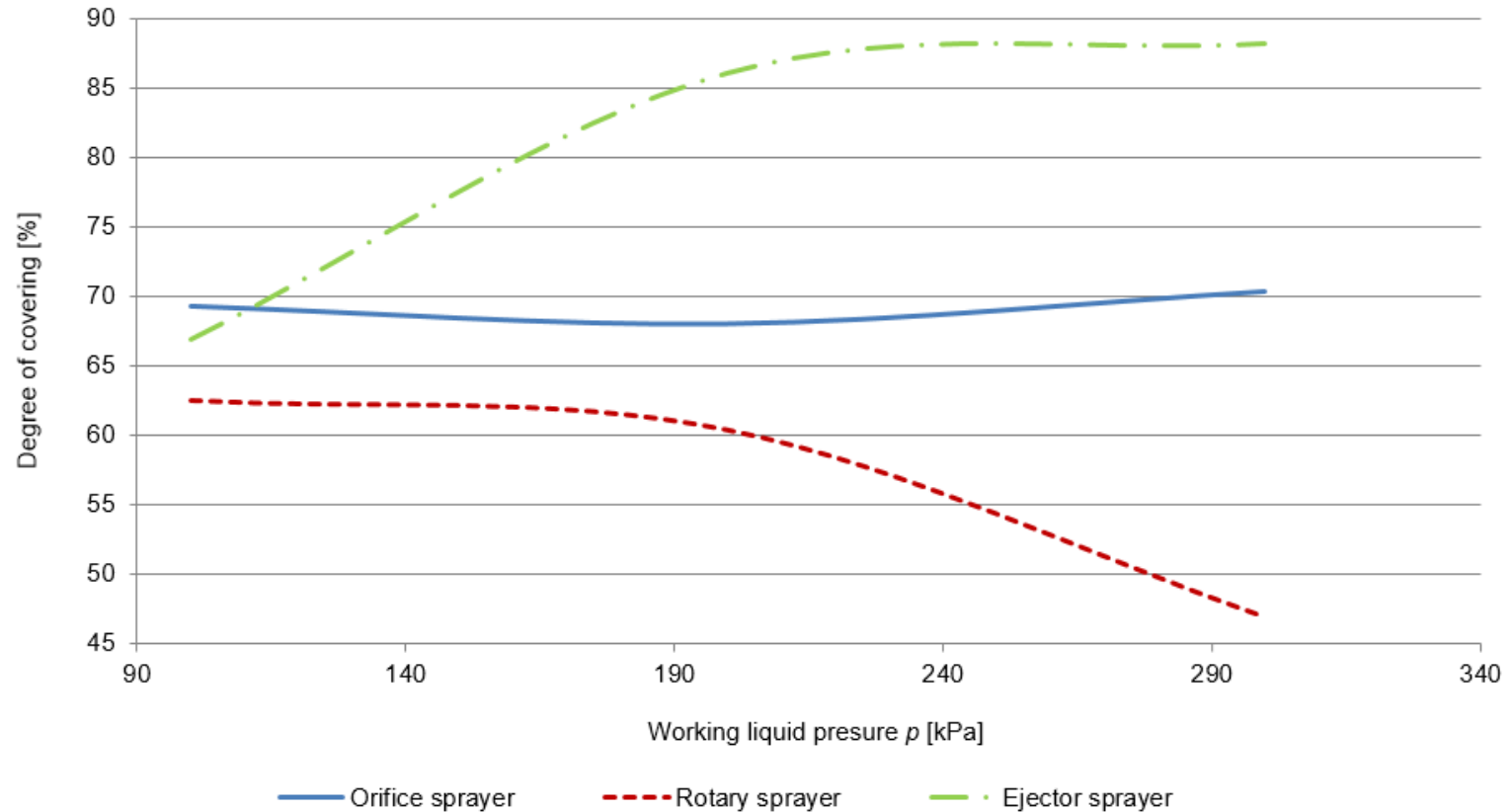

Figure 7. The degree of seed potato covering with the dressing substance for the electronically controlled sprayer valve with an additional supply of compressed air positioned at a distance $S$ of $50 \mathrm{~mm}$ from the seed potato fall axis. 


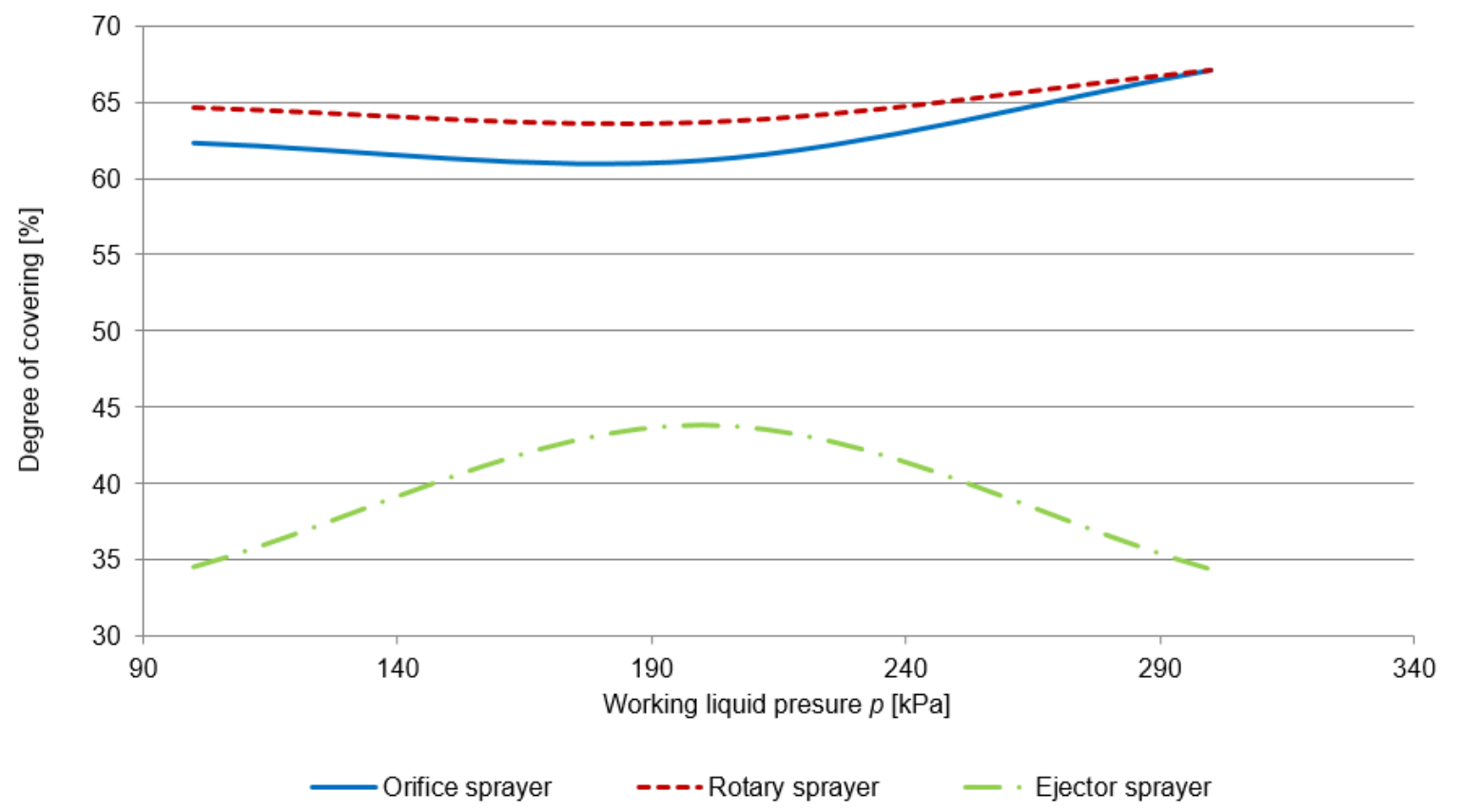

Figure 8. The degree of seed potato covering with the dressing substance for the electronically controlled sprayer valve with an additional supply of compressed air positioned at a distance $S$ of $100 \mathrm{~mm}$ from the seed potato fall axis.

In order to verify the results of laboratory tests a field trial was conducted. Elements of the laboratory facility were modified to carry out a trial on a KORA planter manufactured by UNIA Company (Grudziadz, Poland) (Figure 9). Apart from that, a controller with a set of sensors was devised to control the dressing machine (Figure 10) by setting the delay time and the time of engagement of novel solenoid valves. The trial was conducted on class $4 \mathrm{~b}$ soil, where the planter unit moved across the field only once at a distance of $330 \mathrm{~m}$. The unit consisted of a tractor (model: Zetor PROXIMA, Brno, Czech Republic), a twin-row planter (model: KORA, UNIA Company, Grudziadz, Poland), and a prototype of a mobile dressing machine with novel valves. The seed potato spraying process is shown in Figure 11. In order to verify the effectiveness of treatment and to find differences between the seed potatoes dressed with a system with novel valves and the ones which were not treated, a test was conducted in a field with an area of $1000 \mathrm{~m}^{2}$, on a farm situated near the town of Kalisz in Poland. A prototype of a seed dressing machine with novel valves with an auxiliary airstream was built and placed on top of the planter. The test was conducted in the first week of April 2015, but its effectiveness was evaluated in the second week of June 2015. During the test, one of the two dosing units was equipped with a new treatment unit shown in Figure 10. It consists of the controller of the novel solenoid valve (A), compressor (B), and a facility for the novel solenoid valves (C) spraying seed potatoes with an intermittent stream of the dressing substance. The control system of novel valves of the seed dressing machine placed on top of the planter, together with optical sensors is shown in Figure 10. Figure 11 shows the process of dressing seed potatoes falling off the planting unit. The novel electronically controlled valve with an auxiliary airstream is circled in the same figure. 


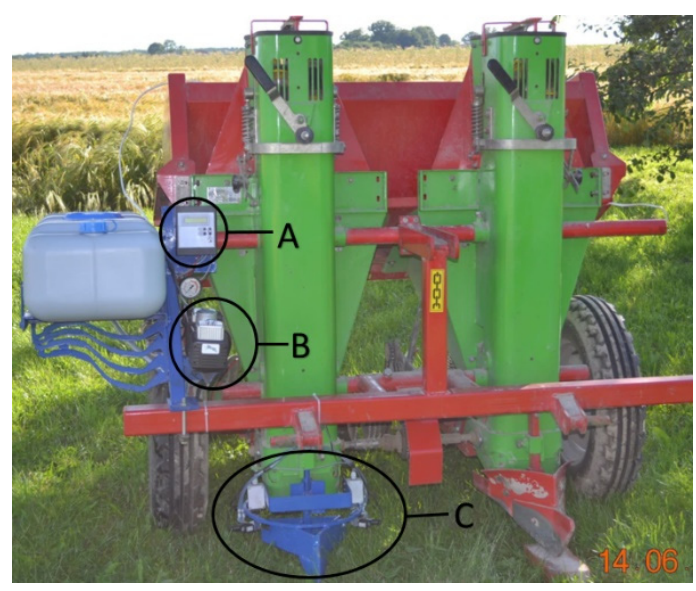

Figure 9. Dressing equipment converted into a KORA planter (UNIA company): A—solenoid valve controller; $\mathrm{B}$ - compressor; $\mathrm{C}$ - the position for placing the solenoid valve with an auxiliary airstream [38].

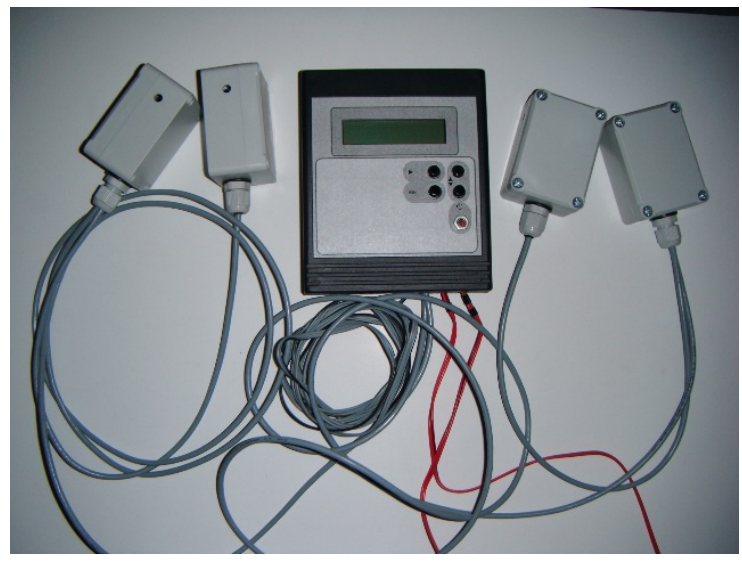

Figure 10. A device controlling a mobile dressing machine placed on planters [29].

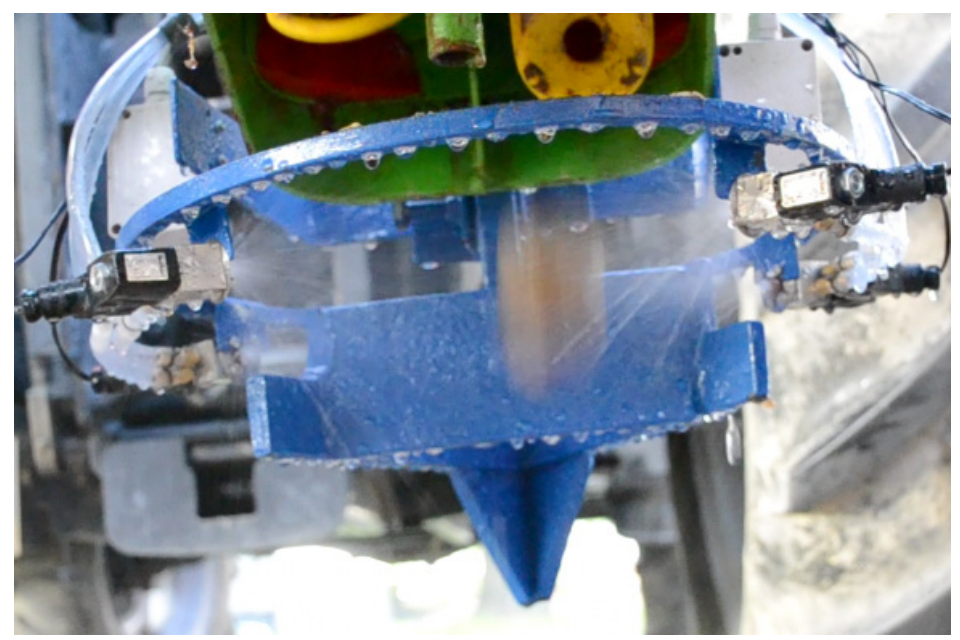

Figure 11. Spraying with a mobile treatment machine. The position of novel solenoid vales with an auxiliary airstream is circled.

The calculations showed that while potatoes were being planted, the valve spraying the dressing substance could be closed for over $80 \%$ of the time. A valve spraying potatoes with intermittent flow of the dressing substance was devised for this purpose. Only the construction with an auxiliary airflow meets the requirements set in the research (Figure 4). 


\section{Discussion}

A similar study on the effectiveness of treatment against fungal diseases was conducted by Andreu and Caldiz [39]. Erlichowski T. [40] conducted similar experiments on seed potatoes treated with Prestige 290 FS. He proved that dressing seed potatoes significantly reduced the occurrence of diseases, and the loss caused by pests feeding on tubers. The laboratory investigations conducted by Iked et al. showed the positive effect of treating seed potatoes with P. oligandrum. The researchers covered seed potatoes with a chemical agent by soaking them in an aqueous solution of P. oligandrum. Next, the seed potatoes were left in the sun to dry. When they were examined after three weeks, the number of seed potatoes with spores decreased by $60 \%$. The field trials confirmed the results of laboratory tests because there was a lower incidence of fungal diseases in the plants treated with P. oligandrum [41].

Currently, research is conducted to show the exact amount of the chemical that can be the saved per 1 hectare. It seems that at least $50 \%$ can be saved. The novel valves with intermittent flow of the working liquid will allow saving $2 \mathrm{~L}$ of the chemical agent, as compared with $4 \mathrm{~L}$ with the standard use of the chemical agent.

The research results proved that it is possible to reduce the amount of chemicals falling on the soil while spraying potatoes. The treatment efficiency was satisfactory-up to $90 \%$. Figure 12 shows the amount of the chemical agent (treatment product) sprayed from the solenoid valve without an auxiliary airstream and from the one with an auxiliary airstream while planting potatoes. The chart shows the results for the novel valve with a rotary sprayer nozzle. As can be seen, the amount of the chemical applied decreased. Simultaneously, the amount of waste pesticides polluting soil and ground waters was reduced. To sum up, the seed dressing machine with novel valves reduced the amount of chemicals, but it did not decrease the degree of seed potato covering with the dressing substance. Therefore, the novel valves used in the treatment machine are environment-friendly and have huge potential for implementation. The field trial showed the functionality of the device. The treatment killed Colorado (potato) beetles at a later stage of plant growth (see Figure 13A). Colorado (potato) beetles continued damaging the plantation in the row where the seed potatoes had been planted without prior treatment (Figure 13B). Further research is planned to check both the novel valves and the effect of the treatment product more precisely in real conditions in a larger area, in accordance with the rules of the research experiment.

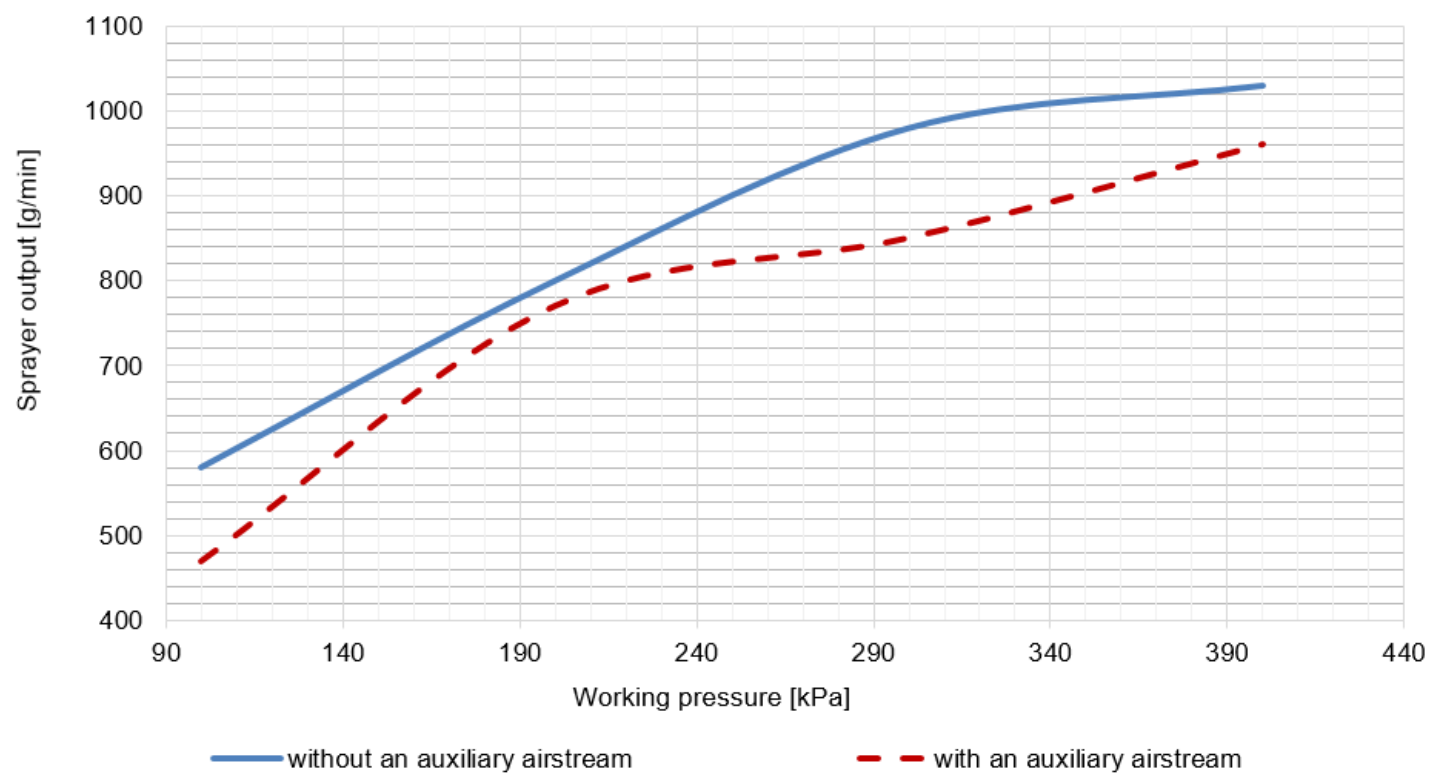

Figure 12. A comparison of the output of the working fluid flowing from the rotary sprayer without an auxiliary airstream (blue line) and from the one with an auxiliary airstream (red dashed line). 


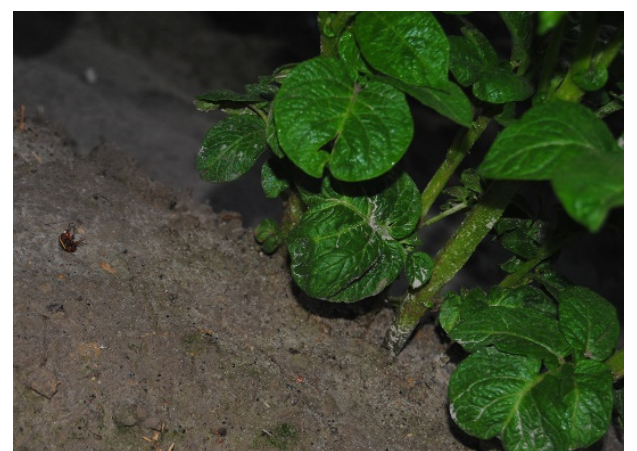

(A)

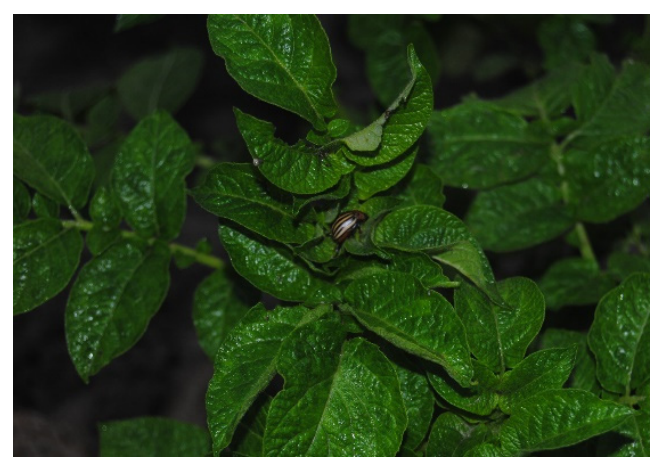

(B)

Figure 13. Yield after the research: (A) - the row of potatoes sprayed with the dressing substance from the mobile machine, (B) - the row of potatoes which was not sprayed with the dressing substance.

\section{Conclusions}

The test results showed that the largest degree of seed potato covering with the dressing substance, i.e. up to $88 \%$, was noted when the valve with an auxiliary airstream and the ejector sprayer was positioned at a distance $S$ of $50 \mathrm{~mm}$ from the seed potato fall path. When the valve was positioned at a distance of $S 100 \mathrm{~mm}$ from the seed potato fall path, the largest degree of seed potato covering with the dressing substance was noted for the orifice and rotary sprayers, i.e., up to $67 \%$.

When the valve without an auxiliary airstream was used, the largest degree of seed potato covering with the dressing substance, i.e., 77\%, was noted for the orifice sprayer positioned at a distance $S$ of $50 \mathrm{~mm}$ from the seed potato fall path. When the valve was positioned at a distance of $S 100 \mathrm{~mm}$ from the seed potato fall path, the degree of seed potato coverage with the dressing substance amounted to $63 \%$. When the distance $S$ increased from 50 to $100 \mathrm{~mm}$, the degree of seed potato covering with the dressing substance decreased for both valve types.

The laboratory test and field trial showed that minor modifications in the construction of the valve, an auxiliary airstream and a mixing insert resulted in almost $90 \%$ of the potato surface covered with the dressing substance at an intermittent stream of the working liquid. Such a high degree of covering lets us assume that the amount of chemicals used for dressing seed potatoes can be reduced. Thus, it is possible to cut the costs of cultivation and reduce the emission of chemicals to the environment. This finding was evidenced by the comparison of the degree of seed potato covering and the consumption of chemical agents for the novel valves and the ones without the control system, which sprayed the working liquid in a continuous flow.

The research showed that when the first version of the valve (without auxiliary airstream) was used, the highest degree of seed potato covering with the dressing substance, i.e., up to $78 \%$, was noted for orifice sprayers, which could be used in valves without output control system. However, the use of rotary sprayers is not recommended, because the degree of seed potato covering with the dressing substance was very low (the highest value for this option did not exceed $67 \%$ ).

When the ejection sprayers were used, the degree of seed potato covering with the dressing substance was $60 \%$ for the first version of the valve (without an auxiliary airstream). When the valve with an additional supply of compressed air was used, the degree of seed potato coverage with the dressing substance increased to $90 \%$. Therefore, it is legitimate to use such sprayers in novel valves dedicated to mobile treatment machines.

The use of the novel construction of the valve with an auxiliary airstream enabled an intermittent flow of the working liquid. Thus, the emission of chemicals used for dressing can be reduced, for the benefit of the natural environment, whereas the degree of seed potato covering with the dressing substance will still be very high if the ejector sprayer is used. The recommended distance $S$ of the valve from the seed potato fall path is $50 \mathrm{~mm}$ to ensure the highest degree of coverage with the dressing substance. 
At present, there is no similar solution described either in scientific publications or in patent documentation. Also, none of the company's manufacturing potato cultivation machinery has an identical solution in its offer.

Author Contributions: Conceptualization, Ł.G.; methodology, Ł.G., K.P.; software, Ł.G.; validation, Ł.G., K.P. and K.K.; formal analysis, Ł.G., K.K.; investigation, Ł.G., K.P.; resources, Ł.G., K.P.; data processing, Ł.S.; writing-original draft preparation, Ł.G. and Ł.S.; writing-review and editing, Ł.G., K.K. and K.P.; visualisation, Ł.G.; supervision, K.K. and S.K.; project administration, S.K.; fund acquisition, Ł.G., Ł.S. and S.K. All authors have read and agreed to the published version of the manuscript.

Funding: The authors are grateful for the financial support provided by the Poznan University of Technology, Poland, within the fund no. 05/51/DSMK/3537.

Conflicts of Interest: The authors declare no conflict of interest.

\section{References}

1. FAO. FAOSTAT Database. 2013. Available online: http://faostat.fao.org (accessed on 5 October 2018).

2. Serageldin, I. Biotechnology and food security in the 21st century. Science 1999, 285, 387-389. [CrossRef] [PubMed]

3. Rizvi, S.; Sharma, R.; Srinivas, T.; Manan, A.; Osmanzai, A.; Siddiqui, S.; Wadan, K.; Hakimi, N.; Rahmani, A. Comparative evaluation of local and improved crop varieties through farmers' participation on resource-poor farms in Afghanistan. Acta Agron. Hung. 2012, 60, 11-20. [CrossRef]

4. Reddivari, L.; Wang, T.; Wu, B.; Li, S. Potato: An anti-inflammatory food. Am. J. Potato Res. 2019, 96, 164-169. [CrossRef]

5. Sen, D.; Rakshit, A.; Sarkar, N.C.; Ghosh, D.C.; Roy, S.K.B. Effect of transplanting dates and spacing on yield attributing character, productivity and economics of potato cultivation through true potato seed (TPS) technology. Ital. J. Agron. 2010, 5, 35-42. [CrossRef]

6. Bruinsma, J. World Agriculture: Towards 2015/2030; An FAO Perspective; Food and Agriculture Organization of the United Nations (FAO): Rome, Italy, 2003.

7. Scott, G.J. Maps, models, and muddles: World trends and patterns in potatoes revisited. Potato Res. 2002, 45, 45-77. [CrossRef]

8. Walker, T.; Thiele, G.; Suarez, V.; Crissman, C. Hindsight and Foresight about Potato Production and Consumption; International Potato Center (CIP): Lima, Peru, 2011; Available online: https:/cgspace.cgiar.org/handle/10568/ 67213 (accessed on 9 January 2020).

9. Birch, P.R.J.; Bryan, G.; Fenton, B.; Gilroy, E.M.; Hein, I.; Jones, J.T.; Prashar, A.; Taylor, M.A.; Torrance, L.; Toth, I.K. Crops that feed the world 8: Potato: Are the trends of increased global production sustainable? Food Secur. 2012, 4, 477. [CrossRef]

10. Rosenzweig, C.; Phillips, J.; Goldberg, R.; Carroll, J.; Hodges, T. Potential impacts of climate change on citrus and potato production in the US. Agric. Syst. 1996, 52, 455-479. [CrossRef]

11. Kleinwechter, U.; Gastelo, M.; Ritchie, J.; Nelson, G.; Asseng, S. Simulating cultivar variations in potato yields for contrasting environments. Agric. Syst. 2016, 145, 51-63. [CrossRef]

12. De Frutos Cachorro, J.; Gobin, A.; Buysse, J. Farm-level adaptation to climate change: The case of the Loam region in Belgium. Agric. Syst. 2018, 165, 164-176. [CrossRef]

13. Delbridge, T.A.; Fernholz, C.; King, R.P.; Lazarus, W. A whole-farm profitability analysis of organic and conventional cropping systems. Agric. Syst. 2013, 122, 1-10. [CrossRef]

14. Van Winsen, F.; de Mey, Y.; Lauwers, L.; Van Passel, S.; Vancauteren, M.; Wauters, E. Cognitive mapping: A method to elucidate and present farmers' risk perception. Agric. Syst. 2013, 122, 42-52. [CrossRef]

15. Van Loon, C.D. Integrated crop management, the basis for environment friendly crop protection of potatoes. Neth. J. Plant Pathol. 1992, 98, 231-240. [CrossRef]

16. Hołownicki, R.; Doruchowski, G.; Świechowski, W.; Godyń, A. GOOD PRACTICE_Limiting the Abandonment of Plant Protection Products in Orchard Cultivations; Institute of Horticulture: Skierniewice, Poland, 2015. (In Polish)

17. Nemecek, T.; Dubois, D.; Huguenin-Elie, O.; Gaillard, G. Life cycle assessment of Swiss farming systems: I. Integrated and organic farming. Agric. Syst. 2011, 104, 217-232. [CrossRef] 
18. Boulard, T. Recent trends in protected cultivations-microclimate studies: A review. Acta Hortic. 2012, 957, 15-28. [CrossRef]

19. Mahmood, I.; Imadi, S.R.; Shazadi, K.; Gul, A.; Hakeem, K.R. Effects of pesticides on environment. In Plant, Soil and Microbes: Volume 1: Implications in Crop Science; Springer: Berlin, Germany, 2016; pp. 253-269, ISBN 9783319274553.

20. Przybył, K.; Boniecki, P.; Koszela, K.; Gierz, Ł.; Łukomski, M. Computer vision and artificial neural network techniques for classification of damage in potatoes during the storage process. Czech J. Food Sci. 2019, 37, 135-140. [CrossRef]

21. Hofmann, L.M. La sarna plateada (Helminthosporium solani [Dur. \& Mont.]), una enfermedad de creciente importancia en papa. Agron. Mesoam. 2009, 20,417-431.

22. Kulmatycka, J.; Leszczenko, P.; Malec, K. Rizoktonioza ziemniaków [Rizoctonia-Disease of Potatoes]. Acta Agrobot. 1955, 3, 1. [CrossRef]

23. Ansari, M.A.; Evans, M.; Butt, T.M. Identification of pathogenic strains of entomopathogenic nematodes and fungi for wireworm control. Crop Prot. 2009, 28, 269-272. [CrossRef]

24. Kempenaar, C.; Been, T.; Booij, J.; van Evert, F.; Michielsen, J.M.; Kocks, C. Advances in variable rate technology application in potato in the Netherlands. Potato Res. 2017, 60, 295-305. [CrossRef]

25. Gierz, S. Review of potato treatment equipment on the domestic market. Ziemniak Polski 2011, $21,37-42$. (In Polish)

26. Ossowski, J. Prevention of rhizoctotonization (Rhizoctonia solani) in potato crops. Ziemniak Polski 2011, 2, 24-26. (In Polish)

27. Gierz, S.; Kęska, W.; Gierz, Ł. Laboratory evaluation of the degree of covering of potato tubers with liquid dressing in aspect of ecological requirements. J. Res. Appl. Agric. Eng. 2011, 56, 88-91.

28. Rogacki, R.; Szulc, T. Potatoes cultivation in Poland in the aspect of requirements from potato planters. J. Res. Appl. Agric. Eng. 2006, 51, 28-32. (In Polish). Available online: http://yadda.icm.edu.pl/yadda/element/ bwmeta1.element.baztech-article-BAR0-0019-0085 (accessed on 9 January 2020).

29. Gierz, S.; Kęska, W.; Gierz, Ł. Electronic Control System for Valves of the Mobile Sorting and Cleaning Machine; PL 223195; UPRP: Ponce, Puerto Rico, 2015.

30. Gierz, S.; Kęska, W.; Gierz, Ł. Optical method for measuring the degree of potato bulbs coverage by liquid dressing. J. Res. Appl. Agric. Eng. 2013, 58, 44-50.

31. Gierz, S.; Kęska, W.; Gierz, Ł. Atomizer Valle; PL 219769; UPRP: Ponce, Puerto Rico, 2014.

32. Du Vall, M.; Ożegalska-Trybalska, J. The right to gain patent and its protection. In Industrial Property Law. The System of Civil Law; Skubisz, R., Ed.; Wolters Kluwer Polska: Warsaw, Poland, 2017; p. 2.

33. Du Vall, M. The right to gain patent and its protection. In Studies in Private Law; CH Beck: Warsaw, Poland, 2010.

34. du Vall, M.; Żakowska-Henzler, H. Invention. In Studies in Private Law; CH Beck: Warsaw, Poland, 2011.

35. Gierz, Ł.; Semkło, Ł.; Przybył, K.; Przybył, J.; Frankowski, J.; Koszela, K.; Boniecki, P.; Kujawa, S.; Idziaszek, P. The selection of a representative substance for image analysis assessment. In Proceedings of the International Society for Optical Engineering, Guangzhou, China, 11-13 May 2019; Volume 11179. [CrossRef]

36. Gierz, Ł.; Gierz, S.; Koszela, K.; Fojud, A.; Boniecki, P.; Gawałek, J. Validation of a photogrammetric method for evaluating seed potato cover by a chemical agent. In Proceedings of the International Society for Optical Engineering, Shanghai, China, 11-14 May 2018; Volume 108064.

37. Wiprol. Wiprol Products. 2013. Available online: https://www.wiprol.pl (accessed on 5 October 2018).

38. Gierz, Ł.; Gierz, S. Electronically Controlled Mobile Wet Dresser; PL 226004; UPRP: Ponce, Puerto Rico, 2016.

39. Andreu, A.B.; Caldiz, D.O. Early management of late blight (Phytophthora infestans) by using systemic fungicides applied to seed-potato tubers. Crop Prot. 2006, 25, 281-286. [CrossRef]

40. Erlichowski, T. The Effect of Tuber Treatment with Prestige 290 FS on the Healthiness and Yield of Potato; Plant Breeding and Acclimatization Institute: Bonin, Japan, 2003; Volume 228, pp. 225-231.

41. Ikeda, S.; Shimizu, A.; Shimizu, M.; Takahashi, H.; Takenaka, S. Biocontrol of black scurf on potato by seed tuber treatment with Pythium oligandrum. Biol. Control 2012, 60, 297-304. [CrossRef] 